\title{
Low-Level Laser Action on Orthodontically Induced Root Resorption: Histological and Histomorphometric Evaluation
}

\author{
Eliziane Cossetin Vasconcelos ${ }^{1 *}$, Jose Fernando Castanha Henriques ${ }^{2}$, Marinês Vieira Silva Sousa ${ }^{2}$, Rodrigo \\ Cardoso de Oliveira ${ }^{2}$, Alberto Consolaro' ${ }^{2}$, Arnaldo Pinzan², Fernanda Pinelli Henriques ${ }^{2}$, Caroline Nemetz \\ Bronfman $^{2}$
}

${ }^{1}$ Federal University of Sergipe, Aracaju - SE, Brazil

${ }^{2}$ Bauru Dental School, University of São Paulo, Bauru - SP, Brazil

\section{*Correspondence to \\ Eliziane Cossetin Vasconcelos, DDS; \\ Federal University of Sergipe, Brazil. \\ Tel: +5579991412399; \\ Email: elizianecv@gmail.com}

Published online 18 July 2016

\begin{abstract}
Introduction: Studies have been conducted to develop a means of preventing, controlling or reducing orthodontically induced root resorption. Phototherapy has demonstrated effectiveness as an anti-inflammatory and, considering the inflammatory origin of this pathology, this study evaluated the effects of laser on root resorption.

Methods: The research was conducted among 54 80-day-old male Wistar rats, with weights of $280 \pm 40 \mathrm{~g}$. Phototherapy consisted of a diode laser (Ga-Al-As), calibrated with a wavelength of $808 \mathrm{~nm}$, an output power of $100 \mathrm{~mW}, 2.1 \mathrm{~J}$ or $96 \mathrm{~J}$ of energy and area of $0.0028 \mathrm{~cm}^{2}$. The application was continuous, punctual and with contact. The left first maxillary molar was moved by a super-elastic closed spring with a pre-calibrated and constant force of $25 \mathrm{~g}$. The specimens were irradiated every 48 hours, totaling three or six times, depending on the group to which they belonged. Euthanasia was made in the 7 th or 10th day after the onset of movement. The histological and histomorphometric examination was performed with sections of $6 \mu \mathrm{m}$ stained with hematoxylin and eosin (H\&E).

Results: Considering the dosimetry studied, when compared the subgroups with the same time of movement, 7 or 10 days, the low-level laser (LLL) has no statistically significant effect on the root resorption. As expected, differences were found between groups with different time of movement.

Conclusion: Based on the result, this dosimetry does not seem to be clinically recommended to avoid or reduce inflammatory root resorption, but it also does not induce any root surface alteration.

Keywords: resorption; root; laser therapy; tooth movement; phototherapy.
\end{abstract}

\section{Introduction}

Inflammatory root resorption, a dependent process that may occur when the cementoblast layer is damaged, ${ }^{1}$ can be the result of an inadequate orthodontic stimulus. When the radicular dentine becomes exposed, the inflammatory components and the clasts cells become activated, which can remove this tissue and cause the resorption. ${ }^{2,3}$ This pathology appears in varying intensities ${ }^{4}$ in $90 \%$ of orthodontic treatment cases and has been studied without complete success up to now. . $^{5-9}$

Phototherapy and its biomodulator effect are known to improve inflammatory control, reducing the edema and number of inflammatory cells in the conjunctive tissue. ${ }^{10-12}$ Despite this, few studies are present to demonstrate the low-level laser (LLL) effect on root resorption. The phototherapy action on root resorption was evaluated after dental avulsion, prior to its reimplantation, showing contradictory results. ${ }^{13,14}$ The light emitting diode (LED) effect to reduce inflammatory root resorption was tested and demonstrated success. ${ }^{15}$

Considering the inflammatory origin of root resorption and the satisfactory results of phototherapy in achieving inflammatory control, this study analyzed the laser diode effect, with two different energy densities, over the root resorption induced by tooth movement in rats.

\section{Methods}

Fifty-four 80-day-old male Wistar rats that weighed 280$320 \mathrm{~g}$ were used for this experiment. During the experimental period, the animals remained inside appropriate cages at a constant temperature that ranged between $20^{\circ} \mathrm{C}$ and $24^{\circ} \mathrm{C}$, in a 12 -hour light/dark environment. They were also provided with food and water ad libitum.

The animals were divided into two groups: experimental 
(E), with 36 specimens, and control (C), with 18 specimens. The experimental group (E) was divided into two subgroups of 18 animals each, according to the laser irradiation doses, high (HD) or low (LD). Within both groups, half of the sample was euthanized on the seventh day and the other half on the tenth day. The experimental subgroups received laser irradiation every 48 hours, beginning on the day when springs were installed. The subgroups distribution is presented in Table 1 and the irradiation protocol is assessed in Table 2. All procedures were carried out under general anesthesia, with $0.1 \mathrm{~mL} / 100$ $\mathrm{g}$ body weight intramuscular injection of ketamine hydrochloride $100 \mathrm{mg} / \mathrm{mL}$ and xylazine hydrochloride 20 $\mathrm{mg} / \mathrm{mL}$.

A modified model described by Heller and Nanda was used to move the left first maxillary molar in both groups. ${ }^{16}$ The appliance consisted of a super-elastic closed coil spring ( $25 \mathrm{~g}$; wire diameter, $0.15 \mathrm{~mm}$; eyelet diameter, $1.5 \mathrm{~mm}$; GAC International, Bohemia, NY, USA) that was placed between the left first maxillary molar and incisors while using both central maxillary incisors as anchors. The coil was fixed to the teeth with a $0.25 \mathrm{~mm}$ stainless steel wire ligature (Morelli, Sorocaba, SP, Brazil). The closed coil spring was stretched five millimeters until a force of $25 \mathrm{~g}$ was achieved in accord with manufacturer instruction and confirmed by a dynamometer (Zeuzan 300 g, São Paulo, Brazil, PN 800). The teeth were covered by photo-cured resin around the ligature wire to improve the coil spring retention.

A Gallium-Aluminum-Arsenide (Ga-Al-As) laser (Whitening Laser II - DMC, São Carlos, SP, Brazil) was used to generate LLL irradiation. The wavelength was $808 \mathrm{~nm}$ (infrared laser) and a continuous emission regime was used. The output power was set to $100 \mathrm{~mW}$, the optic fiber diameter corresponded to $0.6 \mathrm{~mm}$ and the energy density (ED) was $25 \mathrm{~J} / \mathrm{cm}^{2} /$ point and $580 \mathrm{~J} / \mathrm{cm}^{2} /$ point. Irradiation was applied in three points by the punctual method with contact. The application points were the buccal, palatal and mesio-cervical aspects of the first left maxillary mo-

Table 1. Sample Distribution According to Subgroups, Dental Movement, Irradiation $\left(\operatorname{Low}=25 \quad \mathrm{~J} / \mathrm{cm}^{2}, \quad\right.$ High $\left.=580 \quad \mathrm{~J} / \mathrm{cm}^{2}\right)$, Experimental Time and Number of Specimens Per Subgroup

\begin{tabular}{lcccc}
\hline Subgroups & Movement & Irradiation & Time & Specimens \\
\hline C_7d & No & No & 7 days & 4 \\
C_10d & No & No & 10 days & 4 \\
C_IDM_7d & Yes & No & 7 days & 5 \\
C_IDM_10d & Yes & No & 10 days & 5 \\
E_LD_7d & No & Low & 7 days & 4 \\
E_LD_10d & No & Low & 7 days & 4 \\
E_HD_7d & No & High & 10 days & 4 \\
E_HD_10d & No & High & 10 days & 4 \\
E_IDM_LD_7d & Yes & Low & 7 days & 5 \\
E_IDM_LD_10d & Yes & Low & 10 days & 5 \\
E_IDM_HD_7d & Yes & High & 7 days & 5 \\
E_IDM_HD_10d & Yes & High & 10 days & 5
\end{tabular}

Abbreviations: C, control; E, experimental; d, days; IDM, induced dental movement; LD, low dose; HD, high dose lar. The laser was applied 3 times for each animal during the experimental period, with 48-hour intervals.

The animals were euthanized with an overdose of anesthetic in varying groups at seven and ten days after force application. Their maxillae were submerged in a $10 \%$ buffered formaldehyde solution for 48 hours. After fixation, the samples were decalcified by using EDTA (0.05M; $\mathrm{pH}$ 7.4) at approximately 60 days. ${ }^{17}$ The left maxillary hemi-arches were then divided and included in paraffin, sectioned with a rotary microtome that was $6 \mu \mathrm{m}$ thick, parallel to the occlusal plane of the first molar up to the radicular division. At this point, eight cuts were made and the one with the most expressive tissue events and best material quality was chosen. Finally, the samples were stained with hematoxylin and eosin (H\&E).

A histological evaluation was performed by using a binocular microscope (Olympus BX50, Tokyo, Japan), with a 20x magnification ocular lens. The blades were photographed by using a digital camera (Nikon, Tokyo, Japan) connected to a computer. One blind examiner performed the readings, using the ImageJ $1.45 \mathrm{~s}$ software for histomorphometric analyzes. ${ }^{18}$

The analyzed area corresponded to the buccal distal root. For interpretation, the same parameters were performed in the experimental and control groups. Root resorption was determined by measuring the resorbed area, resorption extension and resorption thickness. The resorbed area was found by reducing the root area outlined inside the resorption focus from the area that virtually outlined the same focus. The proportion of resorption was also registered. The resorption extension considered the summation of all focus of resorption in the extension: it was measured in a straight line between the two more extreme points of the resorbed focus. In order to determine the thickness of resorption and its ratio to the thickness of the root, the root thickness was measured, considering an external virtual line that limited the resorbed focus and continued the root contour to the center of the pulp chamber. The resorption thickness was found using the same ex-

Table 2. Phototherapy Parameters

\begin{tabular}{|c|c|}
\hline Phototherapy Parameters & Values \\
\hline Frequency & $\begin{array}{l}\text { Three irradiation with interval of } 48 \\
\text { hours between them, starting on day } \\
\text { of spring installation }\end{array}$ \\
\hline ED - fluency & $\begin{array}{l}\text { High dose }=580 \mathrm{~J} / \mathrm{cm}^{2} \\
\text { Low dose }=25 \mathrm{~J} / \mathrm{cm}^{2}\end{array}$ \\
\hline Total energy & $\begin{array}{l}\text { High dose }=96 \mathrm{~J} \\
\text { Low dose }=2.1 \mathrm{~J}\end{array}$ \\
\hline Output power & $100 \mathrm{~mW}$ \\
\hline Wavelength & 808 nm \\
\hline Color & Invisible (Infrared) \\
\hline Emission regime & Continuous \\
\hline Optic fiber diameter & $0.6 \mathrm{~mm}$ \\
\hline Distance of application & In contact/punctual \\
\hline Time & $\begin{array}{l}\text { High dose }=2 \min 43 \mathrm{~s} \text { per point }(6 \\
\text { points) } \\
\text { Low dose }=7 \mathrm{~s} \text { per point }(3 \text { points })\end{array}$ \\
\hline
\end{tabular}

Abbreviation: ED, energy density. 
ternal mark at the deepest point of the focus background. To confirm and complete the quantitative analyses, three parameters were instituted: evolutionary phase, 0 - preserved root, 1 - repaired root (could see a cement layer recovering the resorption area), 2 - paralyzed resorption (resorption area present but no osteoclast cells in root contact), 3 - active resorption (resorption area present with osteoclast cells in root contact); resorption thickness, 0 - no focus, 1 - involving $1 / 4$ of the root thickness, 2 - from $1 / 4$ to $1 / 2,3$ - from $1 / 2$ to $3 / 4,4$ - more than $3 / 4$ involved; resorption extension, 0 - no resorption, 1 - involving $1 / 4$ root perimeter, 2 - from $1 / 4$ to $1 / 2,3$ - from $1 / 2$ to $3 / 4,4$ - $3 / 4$ or more involved.

The results were analyzed (STATISTICA version 7), by performing three-way analysis of variance (ANOVA), followed by Tukey test, with a 5\% significance level. The Kappa index was adopted to evaluate the accuracy of the evaluator in the semi-quantitative data. In order to verify the intra-examiner systematic error, a paired $t$ test was performed. Dahlberg formula was used to estimate the casual error. It was implemented in $30 \%$ of the sample, randomly, with a 30-day interval between measurements.

\section{Results}

No significant difference in weight was found among the subgroups during the initial and final phases.

The results can be seen in Figures 1 and 2, which represent a specimen of each subgroup that was studied.

Comparing the subgroups with no movement; at 7 or 10 days; and high dose and low dose or no irradiation, the laser was innocuous to the roots and, causes no damage.

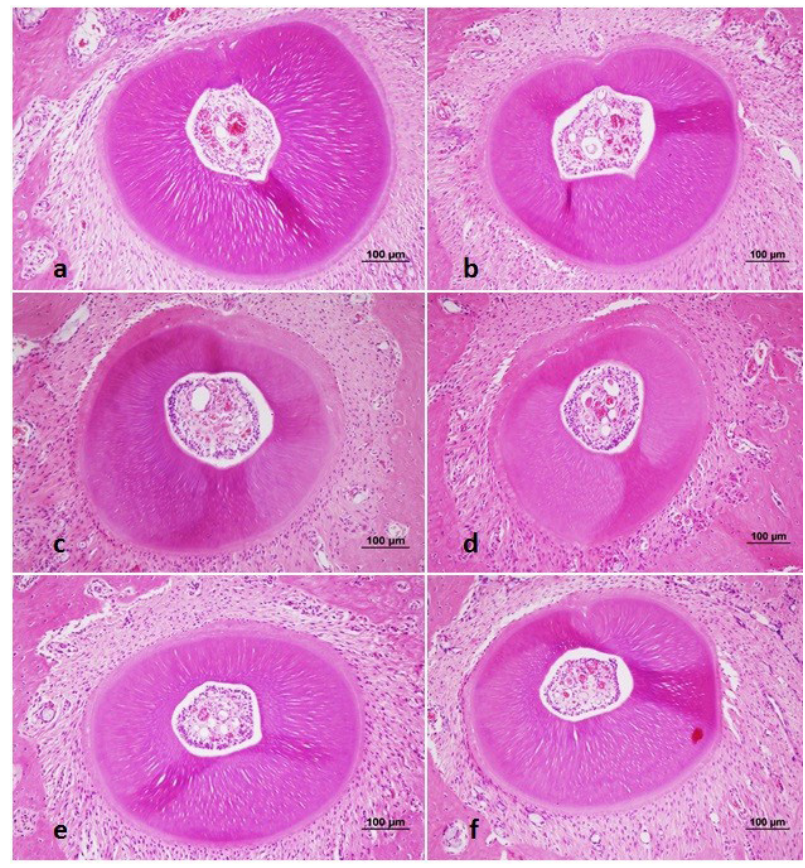

Figure 1. Photomicrography From Subgroups With No Movement. Letters represent each subgroup: (a) Control seven days subgroup; (b) Control ten-day subgroup; (c) High dose seven-day subgroup; (d) High dose ten-day subgroup; (e) Low dose seven-day subgroup; (f) Low dose ten-day subgroup. X200. HE.
No statistical or descriptive difference among the categories was found.

In the same way, comparing the subgroups with induced dental movement, the subgroup E_IDM_HD_10D revealed higher statistically significant values in the following criteria: percentage of total resorbed area, resorption extension and percentage of resorption extension in relation to radicular perimeter (Tables 3, 4 and 5). In the remaining criteria that were analyzed, there was no significant statistical difference.

\section{Discussion}

Among the results found in quantitative and semi-quantitative analysis, there was no statistically significant difference when the subgroups with different irradiation doses were compared, when considering the same experimental time.

The experimental times of seven and ten days were defined based on literature reports. On the seventh day extensive areas of root resorption are expected to be found. After the ninth day, there is a progressive reduction of these phenomena with a reorganization of bone resorption and cemental areas due to the loss of coil spring force. ${ }^{18}$ Employing a descriptive analysis, the results of this study showed similar cellular events at the seven-day group, but differences at the 10-day group, which presented large hyaline areas and clasts cells inside or near from resorbed cavities. The authors believe that this may have occurred because the super-elastic closed coil spring used did not allow a rest period.

Differences occurred among the subgroups moved and

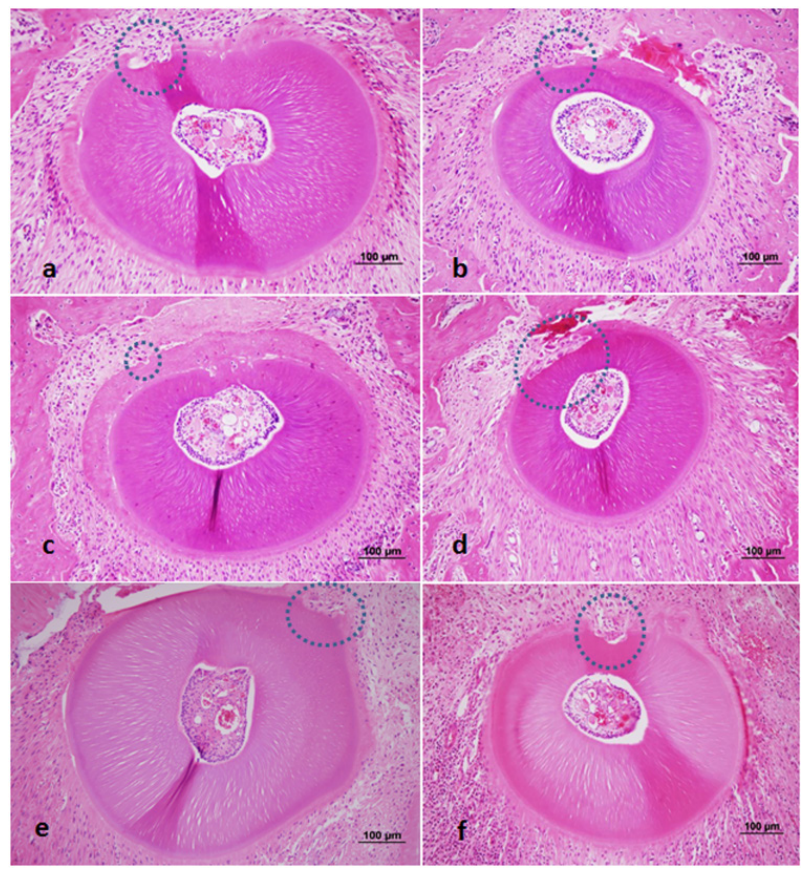

Figure 2. Photomicrography From Subgroups With Movement. Letters represent each subgroup: (a) Control seven days subgroup; (b) Control ten-day subgroup; (c) High dose seven-day subgroup; (d) High dose ten-day subgroup; (e) Low dose seven-day subgroup; (f) Low dose ten-day subgroup. X200. HE. 
Table 3. Percentage of Resorbed Area

\begin{tabular}{lcccc}
\hline Dosis & Movement & Time & Mean \pm SD $(\%)$ & N \\
\hline Control & No & 7 days & $0.0 \pm 0.0^{\mathrm{a}}$ & 4 \\
Control & No & 10 days & $0.1 \pm 0.2^{\mathrm{a}}$ & 4 \\
Control & Yes & 7 days & $0.6 \pm 0.7^{\mathrm{ab}}$ & 5 \\
Control & Yes & 10 days & $2.9 \pm 3.5^{\mathrm{ab}}$ & 5 \\
Low & No & 7 days & $0.02 \pm 0.05^{\mathrm{a}}$ & 4 \\
Low & No & 10 days & $0.0 \pm 0.0^{\mathrm{ab}}$ & 3 \\
Low & Yes & 7 days & $1.6 \pm 1.6^{\mathrm{ab}}$ & 4 \\
Low & Yes & 10 days & $2.1 \pm 1.9^{\mathrm{ab}}$ & 3 \\
High & No & 7 days & $0.0 \pm 0.0^{\mathrm{ab}}$ & 3 \\
High & No & 10 days & $0.0 \pm 0.0^{\mathrm{a}}$ & 4 \\
High & Yes & 7 days & $0.2 \pm 0.4^{\mathrm{a}}$ & 5 \\
High & Yes & 10 days & $3.9 \pm 1.8^{\mathrm{b}}$ & 4
\end{tabular}

Abbreviation: SD, Standard deviation; N, number of specimens. * Statistically significant for $P<0.05$

Different letters represent statistically significant differences.

Three-way ANOVA followed by Tukey tests.

Table 4. Extension of Resorption

\begin{tabular}{lcccc}
\hline Dosis & Movement & Time & Mean \pm SD $(\mu \mathrm{m})$ & $\mathbf{N}$ \\
\hline Control & No & 7 days & $0.0 \pm 0.0^{\mathrm{a}}$ & 4 \\
Control & No & 10 days & $13.5 \pm 27.0^{\mathrm{a}}$ & 4 \\
Control & Yes & 7 days & $78.1 \pm 73.8^{\mathrm{ab}}$ & 5 \\
Control & Yes & 10 days & $108.5 \pm 145.6^{\mathrm{ab}}$ & 5 \\
Low & No & 7 days & $12.9 \pm 25.8^{\mathrm{a}}$ & 4 \\
Low & No & 10 days & $0.0 \pm 0.0^{\mathrm{a}}$ & 3 \\
Low & Yes & 7 days & $104.9 \pm 108.3^{\mathrm{ab}}$ & 4 \\
Low & Yes & 10 days & $139.7 \pm 155.0^{\mathrm{ab}}$ & 3 \\
High & No & 7 days & $0.0 \pm 0.0^{\mathrm{a}}$ & 3 \\
High & No & 10 days & $0.0 \pm 0.0^{\mathrm{a}}$ & 4 \\
High & Yes & 7 days & $15.9 \pm 29.7^{\mathrm{a}}$ & 5 \\
High & Yes & 10 days & $243.6 \pm 122.4^{\mathrm{b}}$ & 4 \\
\hline Abbreviation & SD Standard deviation & $\mathrm{N}, \mathrm{number}$ specimens.
\end{tabular}

Abbreviation: SD, Standard deviation; N, number of specimens. * Statistically significant for $P<0.05$

Different letters represent statistically significant differences. Three-way ANOVA followed by Tukey tests.

Table 5. Percentage of Resorbed Extension in Relation to the Radicular Perimeter

\begin{tabular}{lllll}
\hline Dosis & Movement & Time & Mean \pm SD $(\%)$ & N \\
\hline Control & No & 7 days & $0.0 \pm 0.0^{\mathrm{a}}$ & 4 \\
Control & No & 10 days & $0.7 \pm 1.4^{\mathrm{a}}$ & 4 \\
Control & Yes & 7 days & $4.1 \pm 3.9^{\mathrm{ab}}$ & 5 \\
Control & Yes & 10 days & $5.6 \pm 7.4^{\mathrm{ab}}$ & 5 \\
Low & No & 7 days & $0.7 \pm 1.4^{\mathrm{a}}$ & 4 \\
Low & No & 10 days & $0.0 \pm 0.0^{\mathrm{a}}$ & 3 \\
Low & Yes & 7 days & $5.6 \pm 6.2^{\mathrm{ab}}$ & 4 \\
Low & Yes & 10 days & $7.8 \pm 9.0^{\mathrm{ab}}$ & 3 \\
High & No & 7 days & $0.0 \pm 0.0^{\mathrm{a}}$ & 3 \\
High & No & 10 days & $0.0 \pm 0.0^{\mathrm{a}}$ & 4 \\
High & Yes & 7 days & $0.8 \pm 1.5^{\mathrm{a}}$ & 5 \\
High & Yes & 10 days & $14.3 \pm 6.9^{\mathrm{b}}$ & 4 \\
\hline
\end{tabular}

Abbreviation: SD, Standard deviation; N, number of specimens. *Statistically significant for $P<0.05$

Different letters represent statistically significant differences. Three-way ANOVA followed by Tukey tests. not moved; such differences were justified by known microscopic changes after an induction of movement. ${ }^{19,20}$ Furthermore, among subgroups moved for different experimental time and irradiated with the same dose, a variation occurred (Tables 3, 4 and 5). Previous studies that show the evolution of the tissue changes during tooth movement and its resolution explained this result. ${ }^{18-20}$

This review found only one study that assessed the phototherapy on the inflammatory root resorption, but with LED. ${ }^{15}$ Considering that LED and laser phototherapy exhibit similar effects ${ }^{21}$ and the coherence of light generate a benefit particularly in the deeper tissue layers, ${ }^{22}$ these studies were compared. Fonseca et $\mathrm{al}^{15}$ investigated the effect of phototherapy on inflammatory root resorption, in Wistar rats. Their study applied a power density of $4 \mathrm{~J} /$ $\mathrm{cm}^{2}$ on the day two, three and four, with the euthanasia on the seventh day of tooth movement. The movement was achieved with a nickel titanium spring and $50 \mathrm{~g}$ of force on the upper first molars. ${ }^{15}$ The results presented an increase of periodontal tissue repair, reduced inflammation and reduced root resorption by phototherapy, thus contradicting the results of the present study. Despite the fact that the methodology was distinct, the difference found between these two studies could be due to different doses and wavelengths employed.

Currently, it is conclusive that phototherapy causes changes in cellular metabolism, but the way it operates is still being investigated. ${ }^{23}$ The difficulty of finding the correct dose for each therapy is related to the mechanism of the laser action. In drawing an analogy with the pharmacology, each wavelength is thought to correspond to a different drug. Then after the drug is chosen, it is necessary to establish the optimum dose and the best treatment regimen. ${ }^{21}$

The laser effect on the inflammatory response in the control of chronic and acute inflammation has been positive. ${ }^{11}$ It seems to control the number of cells involved in this process and to reduce pro-inflammatory mediators, ${ }^{10}$ especially prostaglandins. ${ }^{24}$

Tooth movement needs the local inflammatory process to occur, and this inflammation can cause the loss of root tissue when the cementoblast layer is lost. ${ }^{25,26}$ The action of the cells involved in the removal process of necrotic tissue and bone tissue, can damage the root in the denuded surface. ${ }^{27}$ Accordingly, it supposes that the same mechanism that causes the acceleration of induced tooth movement stimulates a more intense root resorption, and the opposite would also be true. Nevertheless, some studies confirm this assumption, ${ }^{7,8}$ while others show that the mechanism that regulates tooth movement may be different from the mechanism of the root resorption. ${ }^{6}$ Consequently, it would be possible to accelerate the teeth movement without increasing the root resorption.

The LLL can stimulate osteoclasts ${ }^{28,29}$ during the induced tooth movement, but this effect seems contradictory for root resorption process. Osteoclasts are important to remove the hyaline area, responsible for keeping the resorption process after the interruption of the force. ${ }^{30}$ Suppos- 
edly, a faster removal of the hyaline area could facilitate the tooth movement and the paralyzation of the resorption. Despite this, while removing the hyaline area with greater speed, could also damage the root tissue, enhancing the resorption.

The positive laser effect on the fibroblasts, ${ }^{31}$ collagen matrix ${ }^{32}$ and capillarity, ${ }^{28}$ in the periodontium, may accelerate the repair and rehabilitation of the root fibers, thus reducing the exposed area to the action of osteoclasts and macrophages. ${ }^{33}$ However, the dose in this study showed no statistically significant difference between the irradiated and the control groups. Perhaps the applied doses in this study were ineffective because they are in a neutral or slightly modulator level for the cells in question.

For phototherapy to be effectively used in orthodontics for preventing inflammatory root resorption, the mechanism of the laser action on the pathology and the appropriate dosimetry for humans, must be defined. For that reason, based on the results obtained in this study, its clinical use for this purpose could not be recommended. Even so, it is interesting to note that the wavelength tested show to be safe for tooth movement without causing or stimulating resorption.

It is suggested that future investigation of resorption may be accompanied by the quantification of tooth movement, since the ideal would be that the dose used to prevent resorption would not cause, or could predict, a delay in the movement. Furthermore, a longer experiment is proposed to determine the action of phototherapy in the process of repairing resorbed roots after the removal of the force and with persistence of hyaline regions.

\section{Conclusion}

Based on the result, this dosimetry does not seem to be clinically recommended to avoid or reduce inflammatory root resorption, but it also does not induce any root surface alteration.

\section{Ethical Considerations}

This study was approved by the Ethics on Teaching and Research in Animals Committee of the University of São Paulo under protocol number 010/2012. Authors herein attest that all animal studies undertaken as part of research from which this manuscript is derived, are in compliance with the regulations of our institution and generally accepted guidelines governing such work. Authors warrant that this manuscript contains no violation of any existing copyright or other third party right or any material of an obscene, indecent, libelous, or otherwise unlawful nature and that to the best of our knowledge the manuscript does not infringe the rights of others previous publications. Authors certify that neither this manuscript nor one with substantially similar content under our authorship has been published or being considered for publication elsewhere in any language (neither local nor international journals).

\section{Conflict of Interests}

Authors warrant that any financial interests, direct or in- direct, that exist or may be perceived to exist for individual contributors in connection with this manuscript have been disclosed in the covering letter.

\section{References}

1. Lindskog S, Blomlof L, Hammarstrom L. Comparative effects of parathyroid hormone on osteoblasts and cementoblasts. J Clin Periodontol. 1987;14(7):386-389. doi:10.1111/j.1600-051x.1987.tb01541.x.

2. Brezniak N, Wasserstein A. Orthodontically induced inflammatory root resorption. Part I: The basic science aspects. Angle Orthod. 2002;72(2):175-179.

3. Brudvik P, Rygh P. The initial phase of orthodontic root resorption incident to local compression of the periodontal ligament. Eur J Orthod. 1993;15(4):249-263. doi:10.1093/ ejo/15.4.249.

4. Mohandesan H, Ravanmehr H, Valaei N. A radiographic analysis of external apical root resorption of maxillary incisors during active orthodontic treatment. Eur J Orthod. 2007;29(2):134-139. doi:10.1093/ejo/cjl090.

5. Gonzales C, Hotokezaka H, Karadeniz EI, et al. Effects of fluoride intake on orthodontic tooth movement and orthodontically induced root resorption. Am J Orthod Dentofacial Orthop. 2011;139(2):196-205. doi:10.1016/j. ajodo.2009.05.029.

6. Gonzales C, Hotokezaka H, Matsuo K, et al. Effects of steroidal and nonsteroidal drugs on tooth movement and root resorption in the rat molar. Angle Orthod. 2009;79(4):715-726. doi:10.2319/072108-381.1.

7. Sato M, Grasser W, Endo N, et al. Bisphosphonate action. Alendronate localization in rat bone and effects on osteoclast ultrastructure. J Clin Invest. 1991;88(6):20952105. doi:10.1172/jci115539.

8. Sirisoontorn I, Hotokezaka $\mathrm{H}$, Hashimoto $\mathrm{M}$, et al. Orthodontic tooth movement and root resorption in ovariectomized rats treated by systemic administration of zoledronic acid. Am J Orthod Dentofacial Orthop. 2012;141(5):563-573. doi:10.1016/j.ajodo.2011.11.016.

9. Verna C, Hartig LE, Kalia S, Melsen B. Influence of steroid drugs on orthodontically induced root resorption. Orthod Craniofac Res. 2006;9(1):57-62. doi:10.1111/j.16016343.2006.00342.x.

10. Albertini R, Villaverde AB, Aimbire F, et al. Antiinflammatory effects of low-level laser therapy (LLLT) with two different red wavelengths $(660 \mathrm{~nm}$ and $684 \mathrm{~nm}$ ) in carrageenan-induced rat paw edema.J Photochem Photobiol B. 2007;89(1):50-55. doi:10.1016/j.jphotobiol.2007.08.005.

11. Casalechi HL, Leal-Junior EC, Xavier M, et al. Low-level laser therapy in experimental model of collagenase-induced tendinitis in rats: effects in acute and chronic inflammatory phases. Lasers Med Sci. 2013;28(3):989-995.

12. Pires D, Xavier M, Araujo T, Silva JA Jr, Aimbire F, Albertini R. Low-level laser therapy (LLLT; $780 \mathrm{~nm}$ ) acts differently on mRNA expression of anti- and pro-inflammatory mediators in an experimental model of collagenaseinduced tendinitis in rat. Lasers Med Sci. 2011;26(1):85-94. doi:10.1007/s10103-010-0811-z.

13. Carvalho ED, Costa FT, Campos MS, et al. Root surface treatment using diode laser in delayed tooth replantation: radiographic and histomorphometric analyzes in rats. Dent Traumatol. 2012;28(6):429-436. doi:10.1111/j.16009657.2011.01108.x

14. Saito CT, Gulinelli JL, Panzarini SR, et al. Effect of low-level 
laser therapy on the healing process after tooth replantation: a histomorphometrical and immunohistochemical analysis. Dent Traumatol. 2011;27(1):30-39. doi:10.1111/ j.1600-9657.2010.00946.x.

15. Fonseca PD, de Lima FM, Higashi DT, et al. Effects of light emitting diode (LED) therapy at $940 \mathrm{~nm}$ on inflammatory root resorption in rats. Lasers Med Sci. 2013;28(1):49-55. doi:10.1007/s10103-012-1061-z.

16. Heller IJ, Nanda R. Effect of metabolic alteration of periodontal fibers on orthodontic tooth movement. An experimental study. Am J Orthod. 1979;75(3):239-258. doi:10.1016/0002-9416(79)90272-0.

17. de Oliveira RC, de Oliveira FH, Cestari TM, Taga R, Granjeiro JM. Morphometric evaluation of the repair of critical-size defects using demineralized bovine bone and autogenous bone grafts in rat calvaria. Clin Oral Implants Res. 2008;19(8):749-754.

18. Fracalossi AC, Santamaria MJ, Consolaro MF, Consolaro A. [Experimental tooth movement in murines: study period and direction of microscopic sections]. $R$ Dental Press Ortodon Ortop Facial. 2009;14(1):143-157.

19. Schwarz AM. Tissue changes incident to orthodontic tooth movement. Int J Orthod. 1932;18:331-352.

20. Storey E. The nature of tooth movement. Am J Orthod. 1973;63(3):292-314. doi:10.1016/0002-9416(73)90353-9.

21. Smith KC. Laser (and LED) therapy is phototherapy. Photomed Laser Surg. 2005;23(1):78-80. doi:10.1089/ pho.2005.23.78.

22. Lobko VV, Karu TI, Letokhov VS. [Is the coherence of low-intensity laser light essential for its effect on biological objects?]. Biofizika. 1985;30(2):366-371.

23. Karu T. Primary and secondary mechanisms of action of visible to near-IR radiation on cells. J Photochem Photobiol B. 1999;49(1):1-17.

24. Shimizu N, Yamaguchi M, Goseki T, et al. Inhibition of prostaglandin E2 and interleukin 1-beta production by low- power laser irradiation in stretched human periodontal ligament cells. J Dent Res. 1995;74(7):1382-1388.

25. Andreasen JO. External root resorption: its implication in dental traumatology, paedodontics, periodontics, orthodontics and endodontics. Int Endod J. 1985;18(2):109118.

26. Andreasen JO. Review of root resorption systems and models: etiology of root resorption and the homeostatic mechanisms of the periodontal ligament. In: Davidovitch $\mathrm{Z}$, ed. The biological mechanisms of tooth eruption and root resorption. Birmingham, Alabama: EBSCO Media; 1988:921.

27. Brudvik P, Rygh P. Multi-nucleated cells remove the main hyalinized tissue and start resorption of adjacent root surfaces. Eur J Orthod. 1994;16(4):265-273.

28. Altan BA, Sokucu O, Ozkut MM, Inan S. Metrical and histological investigation of the effects of low-level laser therapy on orthodontic tooth movement. Lasers Med Sci. 2012;27(1):131-140. doi:10.1007/s10103-010-0853-2.

29. Kawasaki K, Shimizu N. Effects of low-energy laser irradiation on bone remodeling during experimental tooth movement in rats. Lasers Surg Med. 2000;26(3):282-291.

30. Brudvik P, Rygh P. Transition and determinants of orthodontic root resorption-repair sequence. Eur J Orthod. 1995;17(3):177-188. doi:10.1093/ejo/17.3.177.

31. Vinck EM, Cagnie BJ, Cornelissen MJ, Declercq HA, Cambier DC. Increased fibroblast proliferation induced by light emitting diode and low power laser irradiation. Lasers Med Sci. 2003;18(2):95-99. doi:10.1089/pho.2009.2732.

32. Habib FA, Gama SK, Ramalho LM, et al. Laser-induced alveolar bone changes during orthodontic movement: a histological study on rodents. Photomed Laser Surg. 2010;28(6):823-830. doi:10.1089/pho.2009.2732.

33. Brudvik P, Rygh P. The repair of orthodontic root resorption: an ultrastructural study. Eur J Orthod. 1995;17(3):189-198. doi:10.1093/ejo/17.3.189. 